\title{
INVESTIGACIONES
}

\section{Alfabetización Corporal. Una propuesta de aula desde la psicomotricidad}

\author{
Corporal Literacy. \\ A classroom proposal based on psycomotor activity
}

\author{
José Ignacio Bolaños Motta ${ }^{a}$, Mónica Alexandra Pérez Rodríguez ${ }^{b}$, \\ Elizabeth Casallas Forero ${ }^{c}$ \\ ${ }^{a}$ Universidad de los Llanos, Colombia \\ jbolanos@unillanos.edu.co

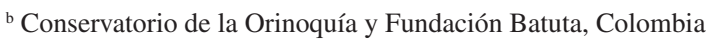 \\ Correo electrónico: monickpr@unicauca.edu.co \\ ${ }^{c}$ Universidad de los Llanos, Colombia \\ Correo electrónico: ecasallas@unillanos.edu.co
}

\begin{abstract}
RESUMEN
El presente estudio se realizó en la Institución Educativa Felicidad Barrios Hernández Vereda el Cocuy, del municipio de Villavicencio (Meta), y tuvo por objetivo principal: Desarrollar un programa de alfabetización corporal como una estrategia educativa planteada desde el paradigma de la psicomotricidad. En términos de la metodología se desarrolló un estudio de tipo cualitativo dentro del campo de la Investigación Acción, se acudió al análisis de diarios de campo y entrevistas manejadas en el proceso. Los participantes fueron menores de grado Preescolar entre los seis y siete años, de la institución Educativa ya nombrada. Los resultados evidenciaron un avance significativo sobre la comprensión de las letras minúsculas del alfabeto. En discusión y conclusiones se confrontan los resultados de la actividad psicomotriz, con algunos estudios y teorías a favor y en contra, para luego formular los logros de la estrategia y su posible aplicabilidad con otras poblaciones.
\end{abstract}

Palabras clave: método, enseñanza, danza, música.

\section{ABSTRACT}

The present study was carried out in the Educational Institution Felicidad Barrios Hernández Vereda el Cocuy, municipality of Villavicencio (Meta), and had as main objective: To develop a body literacy program as an educational strategy proposed from the paradigm of psychomotricity. In terms of the Methodology, a qualitative study was developed within the field of Action Research, we went to the analysis of field diaries and interviews handled in the process. The participants were children from the preschool level between six and seven years old, from the educational institution already named. The results showed a significant advance on the understanding of the lowercase letters of the alphabet. In the part of the discussion and conclusions, the results of the psychomotor activity are compared, with some studies and theories for and against to then formulate the achievements of the strategy and its possible applicability with other populations.

Keywords: method, teaching, dance, music. 


\section{INTRODUCCIÓN AL TEMA DE ESTUDIO}

Nuestras vidas, la de los hombres y mujeres postmodernos, giran no tanto en torno al hacer cosas como al buscar y experimentar sensaciones

(Bauman, 2007: 19).

La presente investigación se desarrolló en el grado de Preescolar de la Institución Educativa Felicidad Barrios Hernández, Vereda El Cocuy, de la ciudad de Villavicencio (Colombia), contexto en el cual niños y niñas con edades entre los seis (6) y los siete (7) años, se encuentran en una etapa de tránsito, desde el garabateo hacia la etapa del "dominio de la escritura convencional" (Scheuer, De la Cruz \& Iparraguirre, 2010), quienes además, al principio del proceso investigativo, conocían solamente las consonantes $m, p$, y $s^{1}$.

El proyecto tuvo por objetivo generar un primer acercamiento a los procesos escolares en la Lengua Castellana a través del método denominado Alfabetización Corporal, proceso que abarcó el año académico 2017 y dentro del presente estudio se buscó desarrollar la siguiente pregunta de investigación: ¿Cómo hacer del cuerpo de los niños, un elemento mediático para el aprendizaje del alfabeto castellano? La estrategia general de la investigación contó a nivel general con cuatro momentos: 1- La creación y diseño del movimiento, 2- La comprensión del estado de alfabetización de los estudiantes, 3- La aplicación del método en el aula de clase, y 4- Análisis cualitativo de los resultados obtenidos con posterioridad a la aplicación del método, una vez implementado y puesto a prueba. Todo lo anterior, enfocado a la inicial creación de un método denominado alfabetización corporal. Más que resolver un problema del curso en particular, se pretendió ofrecer solución a un problema a nivel general en la primera infancia; particularmente en los cursos de Primero Primaria; se hace referencia a la dificultad del niño(a) para generar procesos de escritura, dada la ausencia de un primer acercamiento al alfabeto durante la etapa de Transición, periodo antecedente al curso Primero en el modelo escolar colombiano, etapa que suele estar más basada en lo vivencial o experiencial, que en el aprendizaje ${ }^{2}$, con justas razones.

El modelo de enseñanza de la escritura, desarrollado en la escuela referenciada, estaba centrado en la actividad tiza-tablero, con la guía responsable del docente sobre los "movimientos manuales" (Scheuer et al., 2010: 1084); para la escritura se hace referencia a pliegues con lápiz: vertical, horizontal, inclinado y curvo, que corresponden a los trazos tradicionales (Kellogg, 1970) para la enseñanza de las letras del alfabeto, actividades que en conjunto indican un primer acercamiento de la niñez, de tal forma que se logre pasar del garabateo a una posterior alfabetización inicial (Fitzgerald \& Shanahan, 2000). En concordancia con el modelo educativo tradicional de la enseñanza de la escritura, el proceso indicaba el uso del pupitre en la perspectiva de vigilar e inmovilizar al estudiante (Bolaños \& Pérez, 2017; Foucault, 2003) asumiendo que, a través de la quietud, se lograba una introyección del conocimiento. De manera contraria a lo expuesto, el ejercicio investigativo pretendió otorgar al maestro un lugar distinto en

\footnotetext{
En términos de la práctica, en la investigación se contó con el apoyo de catorce (14) jóvenes adscritos a actividades relacionadas con la práctica docente en la Universidad de los Llanos, Villavicencio.

2 El autor es consciente que no se acostumbra a enseñar a leer y escribir en la etapa de Preescolar; por tanto, la presente propuesta pretende generar sólo un primer acercamiento a las letras del alfabeto, a partir de una actividad artística y psicomotriz (López, 2013).
} 
el ejercicio con los niños y niñas entendiendo al maestro como un psicomotricista, quien resulta ser "una pieza fundamental en el proceso de intervención. Durante su formación tiene que desarrollar una serie de competencias tanto teóricas como personales, que le permitan utilizar su cuerpo en un proceso interactivo o educativo" (López, 2013: 12) asumiendo de esta manera que:

El pedagogo es un teórico y un diseñador de juegos orientados al desarrollo de la inteligencia... El pedagogo pasa de ser un enseñante a un diseñador y ejecutor de criterios de acción orientados a garantizar el logro de metas o ideales, en concordancia con el tiempo y los recursos disponibles (Maldonado, 2012: 27- 43).

Si bien los procesos de lecto-escritura en la primera infancia suelen estar enfocados a generar un desarrollo de la motricidad fina en términos del movimiento de la mano sobre el papel, en el marco de este estudio — y de manera contraria y premeditada—, se diseñó un método de enseñanza del alfabeto en el cual se realizaría una singular escritura del alfabeto a través de movimientos amplios (motricidad gruesa) y con la ayuda de las extremidades del cuerpo, actividad dancística a la que se le denominaría como Alfabetización corporal.

Dichos movimientos serían eventualmente sistematizados a través de un sistema de análisis del movimiento (Stathopoulou, 2011) denominado como Teoría de Labán o Método Labán, proceso al cual se le puede definir como: "un modelo de análisis del movimiento destinado a generar una toma de conciencia sobre las cualidades del movimiento escénico y la danza, y a través del uso consiente de la energía en el movimiento" (Lombardo, 2012:17). Dentro de esta propuesta se diseñó la forma como se escenificaría cada una de las letras del Alfabeto Castellano, se sistematizaron los movimientos y posteriormente se hizo uso del lenguaje sugerido por Rudolph Labán (2003), en la perspectiva de generar un análisis y una definición lo más precisa posible de cada uno de los movimientos, partiendo de la idea de que existe una relación palabra-movimiento, en tanto que:

Los docentes muestran, con sus propios cuerpos, las posturas y los pasos, para que el movimiento pueda incorporarse y realizarse adecuadamente... El modo de transmisión cuerpo-palabra-cuerpo implica, como es de suponerse, la mediación de la palabra entre los cuerpos... con las palabras se refuerza lo que se muestra, y con ellas se busca la internalización de imágenes que se trasladarán al cuerpo (Mora, 2015: 123).

En consecuencia se propuso al grupo graficar las letras del abecedario, asumiendo como lápiz los cuerpos mismos de los estudiantes, bajo el acompañamiento de múltiples ritmos como el Latín Jazz, Hip hop y el Break Dance (Moraga, Solórzano \& Navarro, 2005), ritmos adscritos al amplio género de las músicas urbanas en donde, más que pensar en la enseñanza y aprendizaje de un estilo dancístico como tal, se realizó un proceso educativo "vinculando el trabajo corporal a los contenidos del aprendizaje escolar" (Mendiaras, 2008, p. 202) y asumiendo la psicomotricidad como:

La psicomotricidad, tanto en sus aspectos teóricos como en su práctica profesional, es una disciplina científica que considera al hombre en su "globalidad" psíquico corporal, estructural y funcional, cuya vivencia tiene un rol fundamental en relación con el bienestar de la persona (Boscaini, 2002: 178). 
En concordancia con lo anterior, se propuso diseñar una actividad como un canal de acercamiento para con la lengua castellana, entendiendo que la motricidad es una "Exploración del ser humano que le lleva al conocimiento de sí mismo" (Berruezo, 2000: 22) al tiempo que, como: "una expresión espontánea y natural en el ser humano utilizada como forma de comunicación e incluso, de aquellos sentimientos que resultan difíciles de verbalizar" (Le Boulch, cit. por Gardner, 1991: 87); espontaneidad proveniente de la capacidad para el desarrollo del movimiento ofrecida por un alfabeto dancístico, del cual algunos de sus movimientos corpóreos estarían relacionados con la Danza Urbana, vista ésta como un "conjunto de expresiones y significaciones artístico-contestatarias que toman lugar en el espacio" (Moraga et al., 2005: 80). Se pretendió entonces, en esta propuesta, transversalizar la enseñanza de la lengua Castellana ${ }^{3}$ y de la Educación Artística, como áreas del conocimiento (Camps, 2012) disponiendo de la didáctica como una práctica social (Zambrano, 2015) y entendiendo que:

Las nuevas concepciones de la didáctica están emergiendo de la investigación sobre la enseñanza como práctica social viva, en los contextos sociales e institucionales en donde ocurren, es decir, a partir de la sistematización y las explicaciones de la práctica pedagógica (Garrido, 2013: 118).

También, como parte del diseño de las actividades (Maldonado, 2012), se tuvo presente que la actividad de la Alfabetización Corporal consistiría en desarrollar una estrategia educativa para la enseñanza de la lengua Castellana, entendiendo que: "La didáctica de la lengua constituye un campo de conocimiento que tiene como objeto el complejo proceso de enseñar y aprender lenguas con el fin de mejorar las prácticas y adecuarlas a las situaciones" (Camps, Guasch \& Ruiz, 2010: 71). Aun comprendiendo la amplia complejidad del ejercicio a desarrollar con los menores, se buscó a toda costa generar un espacio lúdico y de aprendizaje en el cual se pudiesen matricular las emociones en la escuela (Buitrago \& Herrera, 2013), en tanto que el ejercicio se observase como una actividad recreativa, y no como una dimensión o área para la enseñanza y el aprendizaje.

\section{UN POCO DE HISTORIA SOBRE EL MÉTODO}

Rudolf Von Labán —influyente figura del siglo pasado en lo referente al análisis del movimiento-, ayudó en gran parte al desarrollo de la danza moderna; hacia el año 1926 creó un sistema de notación de los movimientos dancísticos basado en la geometría, que es hoy en día conocido como labanotacion, utilizado en beneficio de actividades para el espectáculo (Lizarraga, 2014).

Y es de esta manera como "A Labán debemos, además de sus aportaciones educativas y coreográficas, la creación de un sistema de notación coreográfica útil para la danza y los movimientos escénicos" (Lombardo, 2012: 108), sistema que ha sido también ampliamente utilizado en el deporte en donde su uso se ha dirigido a evaluar los movimientos de los

El trabajo realizado y denominado "alfabetización corporal", se realizó únicamente con las letras minúsculas del abecedario; el motivo de usar las minúsculas es el hecho de que las letras en Mayúscula no poseen muchas curvaturas, lo cual dificultaba en parte el movimiento del cuerpo al momento de danzarlas. 
deportistas (Lizarraga, 2014). Desde lo propuesto por Labán, la danza puede ser un producto de la improvisación y el movimiento del cuerpo no condicionado por el ritmo musical, de tal manera que la música resulta ser un soporte para el movimiento y no un condicionante para el mismo (Lombardo, 2012). Atendiendo a lo expuesto, se optó por la teoría de Labán dado que sus aportes resultan ser invaluables, tanto en el análisis de los movimientos que se realizarían en el proyecto, como para la misma arquitectura del movimiento escénico (Labán, 1984).

\section{MATERIALES Y MÉTODOS}

En un primer momento se acudió a una descripción etnográfica (Geertz, 1992) como una primera indagación sobre la vida escolar, y en ella, las formas como se desarrollaban los procesos de pre-alfabetización en el aula. Dado que se partió de un estudio de contexto, se asume que la presente investigación se desarrolló desde el método inductivo (Pasek, 2008) en tanto que se pretendió desarrollar el método de la Alfabetización Corporal ${ }^{4}$, partiendo de un problema de contexto y hacia un desarrollo de una estrategia para un primer acercamiento por parte de la primera infancia en el ámbito de la educación prescolar.

Con posterioridad, se determinó que la metodología principal a desarrollar sería la IA Investigación Acción (Kolb, 1984; Rodríguez, Herráiz \& Prieto, 2011), dado que es a partir de ella se "permite indagar experiencias reales al estar vinculados con una población y en la perspectiva de una transformación de las prácticas escolares...desde el punto de vista de quienes actúan e interactúan en la situación problema" (Elliot, 2000: 5). Se realizó un análisis de orden cualitativo a veintiséis (26) diarios de campo surgidos de las actividades dancísticas del Alfabeto Corporal, ocho (8) entrevistas a los padres de familia y una entrevista a la docente en ejercicio, con el objetivo de indagar un poco más sobre las percepciones de la comunidad, en torno a esta práctica social de aula (Kemmis, cit. por Rodríguez et al., 2011). A lo anterior se agrega que se realizó un amplio trabajo de observación participante durante las sesiones dancísticas desarrolladas con los escolares. Durante la primera fase del estudio se revisó bibliográfica con el fin de generar un amplio abordaje sobre la teoría de Laban de tal forma de que se pudiese sustentar teóricamente la pertinencia de la propuesta de dicho autor.

\section{RESULTADOS}

A partir del proceso investigativo — realizado a lo largo del año 2017 con la comunidad educativa-, se logró como resultado cualitativo, desarrollar la categoría principal del presente texto, el método denominado: Alfabetización corporal.

\section{Alfabetización Corporal}

Se entiende por Alfabetización Corporal el método para la enseñanza del Alfabeto Castellano en el cual se grafican las vocales y consonantes del idioma, a través de movimientos

Este método se desarrolló como un "aprendizaje experiencial" (Kolb, 1984: 4) proponiendo una alfabetización a partir de una actividad psicomotriz, en donde se pretendería transformar parcialmente la enseñanza tradicional de la Lengua Castellana. 
corporales, empleando un grupo de movimientos previamente diseñados. Desde un principio la presente propuesta planteó la hipótesis de que los niños, al graficar las letras del alfabeto con su propio cuerpo, lograrían generar un considerable avance en su proceso de alfabetización a través de una actividad lúdica y corpórea. Dicha propuesta estaría planteada como un estudio desde la transversalidad disciplinar (Camps, 2012) involucrándose campos diversos como la Educación Artística y la Lengua Castellana en la primera infancia (MEN, 2017). El trabajo de campo se desarrolló a lo largo de ocho (8) meses —-sólo interrumpidos por el periodo vacacional-, a lo largo de los cuales se desarrolló una intervención directa, actividades que fueron analizadas posteriormente a través de los diarios de campo; los datos recolectados gracias a las diversas estrategias de recolección de la información fueron también analizados posteriormente por los investigadores; la estrategia consistió básicamente en el análisis a las experiencias generadas en el aula de clase, indicándose de esta manera un análisis en torno al proceso desarrollado. A nivel bibliográfico se indagó el concepto de Effort, propio de la teoría de Labán (Laban \& Lawrence, 1974), el cual se puede entender como: "un enérgico adelantamiento de poder, físico o mental; un intento laborioso, una lucha... una demostración de poder, una realización [y que] implica a la totalidad de la persona" (Lombardo, 2012: 97). Aunque una definición más simple podría ser: "uso de la energía en el movimiento" (Lombardo, 2012: 17) ${ }^{5}$. Con posterioridad a esta indagación de orden bibliográfico se realizó la creación morfológica de las letras del alfabeto, de tal forma que se lograse desarrollar dicha actividad bajo el precepto de que el cuerpo mismo ocupa "un lugar central en el proceso creativo" (Rodríguez, 2014: 35) y también educativo.

Con posterioridad a algunos trabajos de campo se tomó también la decisión de no establecer una relación directa entre los bits (o ritmo) de las canciones y el movimiento del cuerpo al graficar las letras, pues desde la perspectiva de Labán: "el flujo tiene que ser observado independientemente del tiempo porque su cualidad de libre o sujeto es independiente de la rapidez" (Labán citado por Lombardo, 2012: 115), dando lugar a una actividad de movimiento libre y performado (Loke, Larssen, \& Robertson, 2005). Sobre lo anterior se tuvo muy presente el ideal de que cada estudiante llegase a descubrir "su propio estilo expresivo" (Labán, 2003: 193) partiendo de la homogeneidad suscitada por la morfología de las letras del alfabeto castellano, las cuales se realizaron en su mayoría tomando como referente el tipo de letra Arial, para su mejor comprensión. Con antelación al comienzo de las actividades se hicieron varias visitas al plantel con el objetivo de identificar los saberes aprendidos en la escuela, en torno a la escritura de las letras del idioma castellano, como también los saberes aprendidos en los contextos anteriores a la escolaridad pues en algunos casos los estudiantes "no comienzan de cero, sino que tienen ya un conjunto de conocimientos adquiridos" (Teberosky, 1989: 162).

Asumiendo la propuesta planteada, se dio comienzo a la aplicación del método denominado Alfabetización Corporal ${ }^{6}$, bajo la idea de que "los niños, gracias a estímulos imaginativos pudiesen aprender a utilizar el espacio y el flujo del movimiento de manera

\footnotetext{
Se presenta este grupo de definiciones, pues el término Effort (al ser originario del francés, no posee equivalente preciso en lengua castellana. Se aclara también que el metalenguaje Labaniano destinado a la práctica con los menores, tuvo lugar solo en las planeaciones de los docentes.

$6 \quad$ En lo concerniente a la práctica de aula, existe un formato de video sobre la Alfabetización Corporal (Autor, 2017). [Video Personal]. Este video fue realizado en Villavicencio Colombia. Y puede ser consultado en el siguiente link. https://1drv. $\mathrm{ms} / \mathrm{v} / \mathrm{s}$ !Ah6B4t0AWqEUmXpjkW1M2JyeqsqH
} 
inteligente y dirigirlo a la creación de un movimiento expresivo" (Lizarraga, 2014: 18). La actividad se enfocó hacia la graficación de las letras minúsculas, debido a que la morfología de las letras del idioma Castellano en minúsculas ${ }^{7}$ resulta ser más curvilínea que las letras mayúsculas, sobre las cuales se dificultaba ampliamente la actividad dancística, dada la cantidad de movimientos rectos. Como ayuda didáctica se graficaron, sobre el piso o sobre carteleras, las figuras a realizar con las extremidades, gráficas sobre las cuales posteriormente se desarrolló un acompañamiento sonoro de ritmos como el Latín Jazz, el Pop, el funk, el Break Dance y el Hip hop, todo ello como parte de una propuesta lúdica y de bienestar psicofísico (García, Plevin \& Macagno, 2006).

Sobre lo anterior, y en lo referente a la lúdica, el ejercicio despertaba tanto interés en el estudiantado que una vez el investigador ejemplificaba la letra alfabética, los niños gritaban con entusiasmo el nombre de ésta, realizando la correspondiente postura corporal. En lo que a vestuario se refiere, en la mayoría de los casos los menores usaron el uniforme de la Institución Educativa Felicidad Barrios Hernández, salvo excepciones en que se usaron vestuarios alusivos a la danza urbana, caracterizados por la no homogeneidad, que distingue la mentalidad contestataria y contracultural (Moraga et al., 2005) como es el caso de gorras, zapatillas livianas, camisetas con motivos de superhéroes, manillas y jeans amplios, como una forma de establecer una relación cuerpo-imagen, música-imagen. ${ }^{8}$

En términos del repertorio, se hizo uso de temas musicales muy puntuales como, por ejemplo: Soy Yo de la agrupación colombiana Bomba Estéreo (Estéreo, 2015), U Can't Touch This (MC, Hammer, 1989), Take Five (Brubeck, 1961) y la popular canción Gentleman (PSY, 2014) del cantante Sur Coreano PSY, entre otro compendio de pistas básicas para el desarrollo de la actividad de Alfabetización corporal. Al seleccionar el repertorio se tuvo cuidado de llevar al aula canciones que fueran del gusto popular de las generaciones modernas y que tuviesen al mismo tiempo relación con la danza urbana. Salvo algunos temas conocidos de antemano por la niñez del curso a través de los modernos sistemas de comunicación, el repertorio escogido que resultó nuevo para los menores fue muy bien aceptado por el curso en general, y quizás el favoritismo por los temas musicales facilitó de manera directa o indirecta, la actividad. Los ambientes en que se realizó dicha actividad fueron: el aula de clase, las zonas verdes y las canchas deportivas de la Institución Educativa Felicidad Barrios Hernández, además de algunas zonas verdes.

Al respecto se logró identificar, gracias a las entrevistas con la docente y diálogos con los estudiantes, que una de las consecuencias del entusiasmo de los menores por la actividad era precisamente el hecho que implicaba cambiar de ambiente y para realizar una actividad motriz. En una de las actividades, una de las niñas preguntó al investigador principal: "Profe ¿Hoy vamos a bailar las mismas letras de la clase pasada? Es que esas ya nos las sabemos porque las repetimos con la otra profe", muchos de los estudiantes sugerían ambientes verdes y no las canchas de Baloncesto de la institución, pues el piso les permitía tirarse al piso y recrearse —antes, durante y después_-, de la actividad.

Varios elementos constitutivos de la escuela tradicional como son: lápices, marcadores, el tablero, pupitre y el cuaderno fueron suprimidos del proceso investigativo; esto se debió

Letra Arial, como ya se dijo.

En comunicación personal consignada en diario de campo, mayo de 2017.

En comunicación personal consignada en diario de campo, mayo de 2017. 
a que ya no se trataba de imitar lo que el docente escribía sobre, sino de imitar lo que el docente danzaba en. Si bien se ha creído que la niñez aprende los contenidos gracias a un ambiente de introyección y no de movimiento, la disciplina de la psicomotricidad (López, 2013) tiene otra opinión, afirmando que el niño aprende gracias a las emociones generadas en el movimiento. Una de las percepciones que se observaron en el contexto es el hecho de que la niñez, al encontrarse enclaustrada en el aula escolar, se convierte en un grupo de sujetos deseantes (Foucault, 2012) del placer por el movimiento de su cuerpo, hecho por el cual se generó una actividad que partiera del "sentido kinestésico" en el cuerpo (Labán, 1984), para así propiciar un aprendizaje sensorial corpóreo y que tuviese la posibilidad de generar placer por la actividad aprensiva asumiendo, a manera de hipótesis, que con posterioridad a este ejercicio físico se generaría un plano mental (interno) del alfabeto graficado con el cuerpo, hecho que fue bien recibido por el estudiantado, aspecto éste semejante a lo expuesto por Lizarraga:

El movimiento en los niños es más natural y espontáneo que en los adultos, ya que, con el tiempo, el ser humano va adquiriendo patrones de movimiento impuestos, movimientos aislados y desequilibrados que dificultan la libertad de movimiento... los niños, gracias a estímulos imaginativos pueden aprender a utilizar el espacio y el flujo del movimiento de manera inteligente y dirigirlo a la creación de un movimiento expresivo (Lizarraga, 2014: 18).

Dado que uno de los objetivos de la actividad era finalmente desarrollar una actividad escritural —entendida ésta en su acepción básica de escribir sobre el papel a través del movimiento fino de la mano-, hacia el final de la investigación se realizaron actividades de escritura de las letras sobre una cartelera, de tal forma que se llevara al plano de la escritura propiamente dicha la actividad realizada con el cuerpo a lo largo de siete (7) meses del ejercicio investigativo y didáctico-formativo.

Los escolares elevaron considerablemente su conocimiento en las letras del abecedario castellano, hecho que fue destacado por la maestra en ejercicio, quien hacia el final del año escolar contaba con que los niños conociesen únicamente la $\mathbf{m}$, la $\mathbf{p}$ y la $\mathbf{s}$; no obstante, la mayoría de los niños y niñas contaban ya con un amplio conocimiento en torno a todo el alfabeto del idioma castellano en letras mayúsculas. En palabras de la docente: "yo continúo con este grupo el próximo año en primerito, y lo bueno es que a ellos ya no les va a quedar tan difícil la escritura porque ya llevan buenas bases" ${ }^{10}$. A nivel de las competencias en el aula escolar, se fortalecieron los procesos de educabilidad en el aula escolar, "cuya finalidad es facilitar la maduración psicomotriz en el marco curricular del centro educativo" (Berruezo, 2000: 27), sobre lo cual la docente aseguró verse altamente sorprendida ante el impacto del proceso investigativo sobre sus estudiantes ${ }^{11}$.

Hacia los últimos meses del año escolar - y aunque el agotamiento físico era recurrente durante las sesiones de alfabetización corporal—, se logró realizar el alfabeto corporal completo y en una sola sesión, acto que de repente resultó osado dentro de los propósitos

En comunicación personal consignada en diario de campo, noviembre de 2017.

11 Es de aclarar que la docente en ejercicio adscrita al plantel educativo reveló, a través de una entrevista realizada hacia el final del proceso investigativo, que al principio de la actividad ella "no creía en la propuesta investigativa" (en comunicación personal, noviembre de 2017). 
de la investigación pues, al esfuerzo físico que debían realizar los estudiantes en la jornada, se sumaba el sofocante y cotidiano calor de la ciudad de Villavicencio (Colombia).

Para estas fechas se realizó un acto de socialización ante los progenitores de familia; concluida la actividad, uno de los progenitores se acercó al investigador principal y acto seguido tuvieron un diálogo que concluyó en una de las entrevistas más significativas del proceso. El padre de familia contó al investigador que él mismo y de manera personal, se encargaba de enseñarle a su hija a leer y escribir, de tal forma que ella "no se atrase académicamente"12, y que en un momento en el que ella no había recordado cómo graficar una letra, ella se había levantado de la silla y había empezado a graficar (danzar) las letras con su cuerpo hasta recordarla; luego, ella había meditado inmóvil sobre lo que hizo con su cuerpo, para luego escribirla sobre el papel, situación que había dejado perplejo al padre de familia.

\section{DISCUSIÓN Y CONCLUSIONES}

Una generalización posible - y que se deja como propuesta dentro del presente estudioes el hecho de que el método expuesto no sólo puede aplicarse a otros contextos, sino también a otros idiomas y a través de otros géneros musicales. Una de las limitaciones en el desarrollo del presente método es el hecho de que la persona que colaboró en el proceso - quien era experta en Danza Urbana-, eventualmente debió abandonar la investigación, lo cual ocasionó que parte de las letras del alfabeto quedaran diseñadas y pensadas desde la danza urbana, mientras que otras estuviesen pensadas desde el ejercicio motriz básico de la realización de las letras, sin la intensión dada por la danza urbana en donde se hace uso de: "movimientos acrobáticos en el suelo, del electricboogie (o danza del robot)" (Tijoux, Facuse \& Urrutia, 2012: 3) y del karate entre otros, lo cual se asume que hace más llamativa la propuesta.

Sin embargo, se cree en el valor de la enseñabilidad de la Lengua Castellana a través de la estrategia propuesta, y es necesario aclarar que el logro principal del proyecto no es la propuesta de un dogma en cuanto a la sistematización del movimiento desde la teoría de Laban; por el contrario, la búsqueda principal aquí propuesta es que a través de este método se logre convertir el cuerpo del aprendiz de lengua, en un lápiz. Es de notar que los niños si intuían que la actividad tenía por objetivo que ellos a futuro aprendiesen a escribir; uno de los actores de investigación dijo: "Profe, las letras de la canción yo ya las puedo hacer con lapicero"13, lo cual hizo repensar algo que es apenas lógico, y se trata del hecho de que los niños llevan al plano de la escritura, aquello vivenciado de forma pretérita, y/o, las imágenes que habitan en su mente gracias a las experiencias anteriores al ejercicio de la escritura.

Se ha dicho que la música es un elemento mediador para el procesamiento del lenguaje (Besson \& Schön, 2001), y que las denominadas experiencias musicales ayudan a la primera infancia a mejorar su aprensión del lenguaje dado que, a través de ellas, se llega a una "motivación para comunicarse con el mundo" (Pica, 2009: 2). También existe la crítica por parte de algunos investigadores en cuanto a que el arte no ha de estar enfocado para servir a otras áreas de conocimiento; ello lo justifican pues: "no creemos que la

12 Comunicación personal consignada en diario de campo, noviembre de 2017.

13 Comunicación personal consignada en diario de campo, mayo de 2017. 
educación artística deba justificarse por las habilidades que pueda desarrollar para otras áreas académicas" (Winner, Goldstein \& Vincent-Lancrinp, 2014: 26). No obstante, se cree en el valor de la actividad, no pensada ella como el arte al servicio de la Lengua Castellana, sino como un ejercicio interdisciplinario en el que se involucran la geometría, la danza y la lengua castellana, viéndose las dos últimas mayormente favorecidas a nivel disciplinar. Algo a destacar - y que se encuentra medianamente expuesto en un apartado anterior-, es el hecho de que, cuando los niños dejan la etapa preescolar y pasan a la etapa escolar, se generan procesos de traumatismo en lo que a la escritura se refiere, situación que podría resolverse generando un primer acercamiento de tipo lúdico en la etapa Preescolar, como el aquí planteado.

Ante lo expuesto, el presente estudio se propone como una mediana o amplia solución a este problema. Se requirió de una observación constante sobre la quinestésia de niños y niñas, hacia una aprensión de las letras minúsculas de la Lengua Castellana. El avance resultó ser significativo y los más beneficiados con el proceso fueron los estudiantes con más bajo rendimiento en la institución, hecho que se logró observar en las jornadas de clase y que fue destacado por la maestra en ejercicio hacia el final del periodo académico ${ }^{14}$. Es de esta manera como se asume que se posibilitó un "conocimiento sensible" (Martínez, 2015: 26) a través de la Alfabetización Corporal, asumiéndose que la acción psicomotriz de graficar con el cuerpo las letras del alfabeto fortalece los procesos aprensivos y comprensivos de la lectura, y también de la escritura.

Valdría la pena preguntarse, en investigaciones futuras, si el bajo rendimiento o interés por las actividades escolares en lo referente al aprendizaje de la Lengua Castellana procede de la quietud habitual de las aulas destinadas a la enseñanza de la Lengua Castellana en la escuela tradicional. La alfabetización corporal fue aplicada con niños y niñas de condiciones normales; queda abierta entonces la posibilidad de generar estudios de medición de aprendizaje sobre este tema, como también la posibilidad de desarrollar este mismo método en el ámbito de discapacidad, como es el caso de la población sorda (quienes se comunican gracias a la Lengua de Señas), y la niñez o adolescencia con síndrome de Down.

La investigación aún está en curso, pues se cree que existen nuevos hallazgos dentro de la misma. Se han observado cambios actitudinales hacia la Lengua Castellana y hacia las actividades escolares en general, lo cual implicaría una trascendencia de la actividad psicomotriz, en otros momentos y espacios igualmente importantes del ámbito escolar.

\section{REFERENCIAS BIBLIOGRÁFICAS}

Bauman, S. (2007). Arte ¿Líquido? Madrid: Ediciones Sequitur.

Berruezo, P. (2000). "Hacia un marco conceptual de la psicomotricidad a partir del desarrollo de su práctica en Europa y en España”. Zaragoza: Revista Interuniversitaria de Formación del Profesorado, $\mathrm{N}^{\circ} 37$.

Besson, M., \& Schön, D. (2001). "Comparison between language and music". New York: Annals of the New York Academy of Sciences, 930, 232-258. DOI: 10.1111/j.17496632.2001.tb05736.x.

Bolaños, J., \& Pérez, M. (2017). “¿Por qué nos escogió a nosotros para la práctica coral, si somos tan indisciplinados?". Nodos y Nudos, 5(42), 85-100. https://doi.org/10.17227/nyn.vol5.num42-8031

Boscaini, F. (2002). Nuevas necesidades y nuevas respuestas. El rol de la Psicomotricidad. Málaga:

14 Comunicación personal consignada en diario de campo, noviembre de 2017. 
Editorial Aljibe.

Buitrago, B. \& Herrera, T. (2013). "Matricular las emociones en la escuela, una necesidad educativa y social". Revista Praxis y Saber, 4(8), 87-108.

Camps, A. (2012) "La Investigación en Didáctica de la Lengua en la encrucijada de muchos caminos". Revista Iberoamericana de Educación, 59(1), 23-41.

Camps, A.; Guasch, O. \& Ruiz. U. (2010). "La didáctica de la lengua (las lenguas) y la literatura". Revista Textos. Didáctica de la lengua y de la literatura, 55, 71-80.

Elliot, J. (2000). La investigación Acción en la Educación. Madrid: Ediciones Morata.

Fitzgerald, J. \& Shanahan, T. (2000). "Reading and writing relations and their development". Educational Psychologist, 35(1), 39-50.

Foucault, M. (2003) Vigilar y Castigar. Buenos Aires: Siglo XXI Editores.

Foucault, M. (2012) Historia de la Sexualidad. El Uso de los Placeres. Madrid: Siglo XXI Editores.

García, M.; Plevin, M. \& Macagno, P. (2006). Movimento creativo e danza. Método García-Plevin. Roma: Gremese.

Gardner, H. (1991). "La danza". Kinesis, 2(6).

Garrido Pimenta, S. (2013). "Hacia una resignificación de la Didáctica - Ciencias de la Educación, Pedagogía y Didáctica -. Una revisión conceptual y una síntesis provisional”. Pedagogía y Saberes, (39), 117-139. https://doi.org/10.17227/01212494.39pys117.139.

Geertz, C. (1992). Descripción densa: hacia una teoría interpretativa de la cultura. Barcelona: Editorial Gedisa.

Kellogg, R. (1970). Understanding children's art. En P. Cramer (Ed.). Readings in developmental psychology today. Delmar CA: CRM.

Kolb, D. (1984) Experiential learning: experience as the source of learning and development. New Jersey: Prentice Hall, Inc.

Laban, R. \& Lawrence, F. (1974). Effort. Economy of human movement ( $2^{a}$ ed.). Londres: MacDonald and Evans.

Lizárraga, I. (2014) Análisis Comparativo de la Gramática Corporal del Mimo de Etienne Decroux y el Análisis del Movimiento de Rudolf Labán. Barcelona: Universitat Autònoma de Barcelona.

Loke, L.; Larssen, A. \& Robertson, T. (2005) Labanotation for Design of Movement-Based Interaction. Sydney: University of Technology Sydney.

Lombardo, R. (2012) Análisis y Aplicación de la Teoría de Labán y del movimiento Creativo en la Dirección de Conjuntos Instrumentales en la Formación del Maestro en Educación Musical. Valladolid: Universidad de Valladolid.

López, C. (2013) Psicomotricidad y Motricidad en Educación Infantil. Valladolid: Universidad de Valladolid.

Maldonado, F. (2012) Virtualidad y Autonomía. Pedagogía para la Equidad. Bogotá: ICONK Editorial.

Martínez, C. (2015) “Conocimiento Danzario”. Bogotá: Cuadernos de Música, Artes Visuales y Artes Escénicas/Volumen 10.

MEN. Ministerio de Educación de Colombia (2017) Bases Curriculares para la Educación Inicial y Prescolar. Bogotá. Mysterium. ISBN 978-958-785-067-3. Recuperado de: https://www. mineducacion.gov.co/1759/articles-341880_recurso_1.pdf

Mendiaras, J. (2008) "La Psicomotricidad Educativa: un Enfoque Natural". Zaragoza: Revista Interuniversitaria de Formación del Profesorado, vol. 22, núm. 2.

Mora, A. (2015) "El cuerpo como medio de expresión y como instrumento de trabajo: dualismos persistentes en el mundo de la danza". Bogotá: Cuadernos de Música, Artes Visuales y Artes Escénicas. Volumen 1.

Moraga, G.; Solórzano, M. \& Navarro, H. (2005) Cultura Urbana Hip-Hop. Movimiento contracultural emergente en los jóvenes de Iquique. Valparaíso: Centro de Estudios Sociales, núm. 23. 
Pasek, P. E. (2008). "La construcción del problema de investigación y su discurso". Revista Orbis, $\mathrm{N}^{\circ}$ 9, pp. 135-153.

Pica, R. (2009). Make a little music. Edición Magnética: Young Children, 64(6), 74-75.

Rodríguez, A. (2014) "El cuerpo del artista, Una intervención política en la emisión televisiva". Leioa: AusArt Journal for Research in Art 2 (1). p. 35

Rodríguez, K. C. (2011). Investigación Acción. Métodos de Investigación en Educación Especial. Libro digital.

Rodríguez, S.; Herráiz, N. \& Prieto, M. (2011). Investigación Acción. Métodos de investigación en Educación Especial. Libro digital.

Scheuer, N.; De la Cruz, M. \& Iparraguirre, M. (2010). "El aprendizaje de distintos dominios notacionales según niños de preescolar y primer grado". Revista latinoamericana de Ciencias Sociales Niñez y Juventud 8 (2). Consultado de http://revistaumanizales.cinde.org.co/rlcsnj/ index.php/Revista-Latinoamericana/article/view/92

Stathopoulou, D. (2011). Dance Movement to Architectural Form. Bath: University of Bath.

Teberosky, A. (1989) "Los Conocimientos previos del niño sobre el lenguaje escrito y su Incorporación al aprendizaje escolar del Ciclo Inicial". Revista de Educación, 288, 161-183.

Tijoux, M. Facuse, M. \& Urrutia, M. (2012). “El Hip Hop: ¿Arte popular de lo cotidiano o resistencia táctica a la marginación?" Polis, 11(33), 429-450.

Winner, E.; Goldstein, T \& Vincent-Lancrinp, S. (2014) ¿El arte por el arte? La Influencia de da Educación Artística. México: OCDE.

Zambrano, A (2015). "Pedagogía y Didáctica: Esbozo de las Diferencias, Tensiones y Relaciones de dos Campos". Praxis \& Saber, 7(13), 45-61.

\section{BIBLIOGRAFÍA COMPLEMENTARIA}

Laban, R. (1984). Danza educativa moderna. Barcelona: Paidós.

Laban, R. (2003). Choreutique, en Espace Dynamique. Bruxela: Contredanse.

Lewin, K. (1946) La investigación-acción y los problemas de las minorías. Madrid: Editorial Popular.

\section{Referencias discográficas}

Brubeck, D (1961). Take Five. En Álbum: Time Out [Grabación sonora C. D.] New York: Silvery Moon Studios.

Estéreo, B. (2015). Soy Yo. En Álbum: Amanecer [Grabación sonora C. D.] Bogotá: Sony Music.

MC, Hammer (1989). U Can’t Touch This. En Álbum: Please Hammer, Don’t Hurt ‘Em. [Grabación sonora C. D.]. California. Capitol Records.

PSY (2014). Gentleman. En: Gentleman. [Grabación sonora C. D.]. Seúl. YG Entertainment.

\section{Link Video sobre la actividad}

Video de Alfabetización Corporal [Video Personal] (2017, noviembre 20). Villavicencio Colombia. Recuperado de: https://1drv.ms/v/s!Ah6B4t0AWqEUmXpjkW1M2JyeqsqH 